\title{
Why are childless women childless? Findings from an exploratory study in Victoria, Australia
}

\section{Melissa Graham}

Deakin University

\section{Erin Hill}

Deakin University

\section{Julia Shelly}

Deakin University

\section{Ann Taket \\ Deakin University}

\section{Abstract}

Childlessness in Australia is increasing yet there is limited research exploring women's reasons for childlessness. Previous research has typically examined childlessness within the context of fertility rather than childlessness itself. The limited research that has moved beyond looking at involuntary childlessness has labelled women with a type of childlessness during recruitment rather than exploring women's reasons for childlessness as a part of the research process. The aim of this mixed methods exploratory study $(n=50)$ was to describe women's reasons for childlessness. Findings indicate that almost half of the women did not wish to have children. Reasons for childlessness included: having never wanted to have children; having never been in the 'right' relationship; and being in a relationship where the partner did not want to have children. The findings provide insight into women's 
reasons for childlessness, how they feel about their decision, circumstance and position as a woman in a pronatalist society.

Keywords: Childlessness, women, Australia, pronatalism, social exclusion

\section{Introduction}

Despite Australia being a predominantly pronatalist society (Dever, 2005; Heard, 2006), which encourages procreation (Anderson, 2007; Jackson \& Casey, 2009), childlessness is increasing (Australian Bureau of Statistics, 2008). Consequently, women's lives and reproductive decisions must be navigated and negotiated within a society where motherhood is the prevailing and presumed position for women. The lives of childless women and their reproductive decisions come to be experienced within, and pervaded by, dominant social cultural discourses surrounding femininity, motherhood and reproduction (Earle \& Letherby, 2007; Gillespie, 2000). In pronatalist western culture, motherhood has come to be understood (and presented) as a fixed, natural, fulfilling practice, which is central to female identity (Gillespie, 2000). Thus, childbearing is considered the inevitable and appropriate outcome of adult life (Letherby 1999; Park 2002) and consequently womanhood has become conflated with motherhood (Gillespie 2003).

Childlessness research has traditionally focused on childlessness as a consequence of declining fertility rates (see for example McDonald, 1998), birth rates (see for example Australian Bureau of Statistics, 2007, 2008) and infertility (see for example Letherby, 1999; 2002) rather than on women's reasons for not becoming a mother. As such, it fails to examine women's reasons for childlessness other than because of infertility. It has been posited that the rise in childlessness has been a result of increases in: infertility (involuntary childless) (Seccombe, 1991), although the natural infertility rate has remained at around 7\% (Australian Bureau of Statistics, 2002); the number of women choosing not to have children (voluntary childless) (Cannold, 2004, 2005); the number of women circumstantially childless (Cannold, 2005; Seccombe, 1991); delayed childbearing (Australian Bureau of Statistics, 2008); and the rise of feminism (Gillespie, 2003). Regardless of the reason for the increase in childlessness in recent decades, female childlessness continues to be 
characterised by western society as unconventional, undesirable and socially deviant (see for example Gillespie, 2000; Letherby, 1999; Park, 2002).

However, these arguments are not fully informed by an examination of women's reasons for childlessness. Due to normative pronatalist ideology and discourses, women who do not have children challenge dominant social norms and moral rules (Carey, Graham, \& Shelley, 2009). This in turn leads to issues of stigma and social exclusion. Under different circumstances, different social attributes may lead to exclusion from society at different times and in different places (Taket et al., 2009). Social exclusion is not solely based on economic considerations (Popay et al., 2008); people may be economically active, but excluded from social relations in other ways. The focus on social relations and institutions is useful for understanding how individuals may be disadvantaged due to their incongruence with social norms, as is the case for women without children. In regard to childless women, questions of exclusion are not related to material or economic disadvantage, but rather social deprivation (Carey, et al., 2009).

Women's reasons for childlessness, their pregnancy intentions and the socialcultural context in which these reproductive decisions are made and carried out are important in understanding this growing population group.The limited research that has explored women's views to identify reasons for childlessness (beyond infertility) has yielded: having left it too late to have children (Rowland, 1982; Rowlands \& Lee, 2006); a focus on career and paid work (Campbell, 1985; Ireland, 1993); the rejection of culturally assigned gender roles (Ireland, 1993); and having a partner who did not wish to have children (Veevers, 1980). Much of this research has included qualitative studies where women were selected according to the researchers' pre-defined categories of childlessness (see for example Becker \& Nachtigall, 1992; Daniluk, 2001; Houseknecht, 1979; Marshall, 1993; Mueller \& Yoder, 1997, 1999; Park, 2002; Sabatelli, Meth, \& Gavazzi, 1988; Somers, 1993; Ulrich \& Weatherall, 2000; Veevers, 1980) prior to the commencement of the study rather than exploring or describing women's reasons for childlessness as a part of the research process. The majority of this research on women's reasons for childlessness has been conducted outside of Australia, mainly in the United States of America, Canada and the United Kingdom and the studies discussed above are all over 10 years old and thus may be out-dated given changes in society. 
In contrast, another body of work on childlessness has been based on population census data (see for example Australian Bureau of Statistics, 2008; Berrington, 2004; Biddlecom \& Martin, 2006; Boddingtom \& Didham, 2007, 2009; Dye, 2008; Mosher \& Bachrach, 1982), which defines childlessness as having never given birth. This definition does not take into account women with no biological children but with fostered, adopted or step-children, thus falsely identifying some women as childless when in fact they are mothers. The aim of this paper is to explore women's reasons for childlessness within their reproductive social-cultural context in a sample of childless women during their reproductive years.

\section{Method}

This mixed methods exploratory study was conducted in Victoria, Australia during 2009 and 2010 to collect quantitative and qualitative data related to women's reasons for childlessness, their reproductive histories and experiences. Human Research Ethics approval was granted in September 2009 (HEAG-H 141_09).

\section{Sampling}

Purposive sampling was used to recruit a sample of women living in Victoria, Australia, of reproductive age (25-45 years), who were not currently pregnant, and who had never assumed the role of a mother (including biological, adopted, foster or step-children).In 2008, the mean age of Australian women at the birth of their first child was 28.2 years (Laws, Liz, \& Sullivan, 2010). As such the age range included women across the reproductive years and accounted for the age at which most women have children. Women were recruited through a Victorian based university via an email invitation addressed to all female staff. Women were asked to contact the researchers if they were interested in participating in the study. A plain language statement detailing the purpose of the study and what participation entailed was sent to all women who responded to the email invitation. The women were then contacted again a week later to discuss any questions they had about participation in the study and to determine their eligibility. If the women consented to participate in the study, a time was made for a computer-assisted telephone interview. Twelve women were excluded as they did not meet the inclusion criteria. The total sample consisted of 50 women. 
The mean age of the participants was 39.46 years $(S D=3.02)$. There was no statistically significant difference in age between childlessness intentions (I have never wanted to have children $t=-0.65 ; p=0.54$ and $I$ do not wish to have children $F$ $=0.6 ; p=0.55)$. Most of the women were married (42\%). Thirty-two percent of the women were currently not in a relationship, $12 \%$ were living with a partner but not married, $10 \%$ were in a relationship but not living together and $4 \%$ were either divorced or separated. While sexual preference was not specifically asked, this information was disclosed by some women. As such the sample included both heterosexual and lesbian women.

\section{Measures}

The main variables of interest in this study were divided into two areas: reasons for childlessness and reproductive history and experiences. Items regarding women's reasons for childlessness were developed from the literature which has described childless women as either 'postponers' or 'early articulators' (Maher \& Saugeres, 2007; Tietjens-Meyers, 2001). Two items were used to assess women's childlessness intentions:

- Do any of the following apply to you?

- I do not wish to have children (yes / no / unsure)

- I have never wanted to have children (yes / no)

Reproductive history items included prior pregnancy and outcomes (miscarriage, still birth and termination), pregnancy intentions, fertility, reproductive health conditions and contraceptive practices (Smith, Pitts, Shelley, Richters, \& Ferris, 2007; Women's Health Australia, 2000, 2006). Open-ended questions were included to provide the women with the opportunity to add any additional information they felt was relevant, particularly in relation to reasons for childlessness.

\section{Data collection and analysis}

Data was collected using computer-assisted telephone interviews. Each interview was digitally recorded to allow the verbatim transcription of open-ended questions and to ensure the accuracy of data entry. Responses to the open ended question "/s there any other reason for you not having children that you would like to tell us?" was 
recorded verbatim at the time of the interview and responses to "Is there anything else you would like to tell us?" were transcribed verbatim from the digital recording. Two researchers analysed all data thematically, using deductive coding to identify themes within the data that were evident in the literature, for example, careerfocused women (Campbell, 1985; Ireland, 1993), postponers, a consequence of leaving it too late to have children (Rowland, 1982; Rowlands \& Lee, 2006), and having a partner who did not wish to have children (Veevers, 1980). Additionally, inductive coding was used to identify any emergent themes (Braun \& Clarke, 2006; Liamputtong \& Ezzy, 2005). Following Braun and Clarke's (2006) phases of thematic analysis, the themes were reviewed and further defined to ensure that they made sense in relation to the coded pieces of data as well as across the whole data set. Pseudonyms were assigned to each participant and are reported along with their age.

\section{Results}

Women's reasons for childlessness within the context of their reproductive history and experiences are described in the following section, drawing on both the quantitative and qualitative data collected.

\section{Childlessness intentions}

Almost half of the women reported not wishing to have children (47\%) or having never wanted to have children (48\%). Of the women who reported they did not wish to have children, $81 \%$ also reported they had never wanted to have children. Of those women who reported being 'unsure' to the question 'I do not wish to have children,' $25 \%$ reported having never wanted children. Only $11 \%$ of those who reported 'no' to the question 'I do not wish to have children' also reported having never wanted to have children.

For women who were married, $52.6 \%$ did not wish to have children and $68.8 \%$ had never wanted to have children (Table 1). More than half $(58 \%)$ of the women had completed a higher university degree (Graduate Diploma, Masters or PhD). Thirty percent of the women had completed a Bachelor level degree and the remaining women (12\%) had completed a Certificate or Diploma. For women who had a university Bachelor level degree $66.7 \%$ did not wish to have children and $60 \%$ 
had never wanted to have children. Of the women who had a higher university degree, $40 \%$ did not wish to have children and $44 \%$ had never wanted to have children. Most women (70\%) had an individual income of more than $\$ 52,000$ per year. Two-thirds of the women had a combined household income of more than $\$ 78,000$ per year. In each individual income group, there were a higher proportion of women who did not wish to have children. However, this was not the case for women who had never wanted to have children (41.9\%). A similar pattern was seen for household income (Table 1).

Table 1

Marital Status and Current Annual Income by Childlessness Intentions

\begin{tabular}{|c|c|c|c|c|c|}
\hline & \multicolumn{3}{|c|}{ I do not wish to have children $\%(n)^{\text {ac }}$} & \multicolumn{2}{|c|}{$\begin{array}{l}\text { I have never wanted to } \\
\text { have children } \\
\%(n)^{\text {bd }}\end{array}$} \\
\hline & Yes & No & Unsure & Yes & No \\
\hline \multicolumn{6}{|l|}{ Marital status } \\
\hline Married & $52.6(10)$ & $26.3(5)$ & $21.1(4)$ & $68.8(11)$ & $31.3(5)$ \\
\hline Widowed, divorced or separated & - & $66.7(2)$ & $33.3(1)$ & - & $100.0(3)$ \\
\hline Living with a partner but not married & $100.0(6)$ & - & - & $66.7(4)$ & $33.3(2)$ \\
\hline In a relationship but not living together & $40.0(2)$ & - & $60.0(3)$ & $40.0(2)$ & $60.0(3)$ \\
\hline Not in a relationship & $29.4(5)$ & $35.3(6)$ & $35.3(6)$ & $27.8(5)$ & $72.2(13)$ \\
\hline \multicolumn{6}{|l|}{ Annual income range } \\
\hline \multicolumn{6}{|l|}{ Individual income } \\
\hline Less than $\$ 52,000$ annually & $57.1(8)$ & $7.1(1)$ & $35.7(5)$ & $61.5(8)$ & $38.5(5)$ \\
\hline$\$ 52,000$ or more annually & $41.9(13)$ & $32.3(10)$ & $25.8(8)$ & $41.9(13)$ & $58.1(18)$ \\
\hline \multicolumn{6}{|l|}{ Household income } \\
\hline Less than $\$ 52,000$ annually & $50.0(1)$ & - & $50.0(1)$ & $100.0(1)$ & - \\
\hline$\$ 52,000$ or more annually & $46.5(20)$ & $25.6(11)$ & $27.9(12)$ & $46.5(20)$ & $53.5(23)$ \\
\hline \multicolumn{6}{|c|}{ a Marital status and I do not wish to have children $n=50$} \\
\hline \multicolumn{6}{|c|}{ b Marital status and I have never wanted to have children $n=48$} \\
\hline \multicolumn{6}{|c|}{ c Annual income range and I do not wish to have children $n=45$} \\
\hline \multicolumn{6}{|c|}{$d$ Annual income range and I have never wanted to have children $n=44$} \\
\hline
\end{tabular}




\section{Reasons for childlessness}

Women's reasons for childlessness included having never been in the 'right' relationship (46\%) and being in a relationship where their partner did not want to have children (36\%). Table 2 shows women's reasons for childlessness by their childlessness intentions.

Table 2

Reasons for Childlessness by Childlessness Intentions

\begin{tabular}{|c|c|c|c|c|c|}
\hline & \multicolumn{3}{|c|}{$\begin{array}{l}\text { I do not wish to have children } \%(n) n \\
=42\end{array}$} & \multicolumn{2}{|c|}{$\begin{array}{l}\text { I have never wanted to } \\
\text { have children } \%(n) n=44\end{array}$} \\
\hline & Yes & No & Unsure & Yes & No \\
\hline $\begin{array}{l}\text { Have been in relationships where your } \\
\text { partner did not want to have children }\end{array}$ & $50.0(8)$ & $25.0(4)$ & $25.0(4)$ & $56.3(9)$ & $43.8(7)$ \\
\hline $\begin{array}{l}\text { Economic or financial circumstance have } \\
\text { never permitted it }\end{array}$ & $40.0(2)$ & $20.0(1)$ & $40.0(2)$ & $50.0(3)$ & $50.0(3)$ \\
\hline Have never been in the 'right' relationship & $22.2(4)$ & $27.8(5)$ & $50.0(9)$ & $20.0(4)$ & $80.0(16)$ \\
\hline Insufficient childcare available & $20.0(1)$ & $20.0(1)$ & $60.0(3)$ & $60.0(3)$ & $40.0(2)$ \\
\hline $\begin{array}{l}\text { Work arrangements would make it too } \\
\text { difficult }\end{array}$ & $11.1(1)$ & $22.2(2)$ & $66.7(6)$ & $44.4(4)$ & $55.6(5)$ \\
\hline
\end{tabular}

In addition to the identified reasons for childlessness, women were asked to provide other reasons for their childlessness. Three main themes emerged as women's reasons for childlessness: life desires, concerns, circumstance and choice; health concerns; and age. Each of these emergent themes is presented below with the participants' explanation and justification for how they felt about being childless and their position as a childless woman in society.

Within the theme of life desires, concerns, circumstances and choice some women stated their dislike of children, but most of the women disputed their reason was due to a dislike of children. In fact, they argued that they have many children in their life, for example, "I don't not like kids, I just don't want them for myself" (Isabel, 43). Some women cited their concerns for population growth or their lack of maternal instinct as their reasons for childlessness. Women explained that their partner or husband had expressed a desire to be childfree and they were either 
happy with this decision or not confident enough to challenge it. Other reasons for childlessness provided by the women included: wanting "to be able to live my own life" (Jacinta, 40); "never getting around to it" (Tarya, 40); and "it's a choice, an active decision, career and lifestyle was important" (Olivia, 35). The theme of health concerns was identified by some women as a reason for their childlessness. Health issues, in particular gynaecological health problems (but not infertility) such as menstrual disorders, including fibroids and endometriosis, were reported. The final theme related to age, which was considered by some women as a reason for not having children; they stated not wanting to have a child grow up with an "elderly mother" (Penny, 46), and the fear of "end[ing] up with a child who's got special needs" (Becky, 41) due to the age of conception.

Cutting across and interwoven within these three themes was the women's need to explain how they felt about their childlessness and how they viewed their position in society as a result of being a childless woman. Some of the women were satisfied with their decision to remain childless. For example, women commented "overall I'm perfectly satisfied with my decision" (Ebony, 40) and "it's never been in the back of my mind that I have to have kids...and I still don't regret it" (Eleni, 39). Others, however, felt their decision had become easier with time. For example, "I'm comfortable with my decision to not have children...age makes it easier to be comfortable" (Danielle, 42) and "I have changed my mind from the expectation of having children to now, kind of, probably expecting not to" (Barbara, 43). Others reported it was a conscious decision not to have children and they were satisfied with this decision. As one woman stated "it was a choice I made, it wasn't made for me" (Raylene, 38). Others regarded their childless status as stemming from a lack of decision-making and circumstance. For example, "It's not my choice.... Yeah I would have liked to have had children" (Penny, 46). Not all women were happy about their childlessness. For example, one woman stated her “...main issues have been depression related to childlessness" (Tammie, 40).

Some of the women discussed their position in society as a childless woman. For these women a pronatalist society meant their deviation from the 'norm' was not acceptable and they had to justify their position. One woman commented "people are quite angry that if you can have children you should be having them because other people can't" and "I do feel quite pressured by society to have children, I find that I 
constantly have to justify why I don't have children" (Leah, 35). Furthermore, there was a belief "you feel like you don't have a place in society or the community, like you don't belong anywhere" (Lara, 43). Another woman questioned her identity as a woman and person as she did not have children. She stated "who am I in the world if I don't have children, what kind of woman am I?" (Hannah, 33). However, the women also felt today's society offered more choice to women, for example, "I think women have more choice nowadays, they're not expected to be married by 19 or else they're on the shelf" (Daisy, 44), and "I think I'm actually becoming one of a growing number of people... have chosen not to have kids" (Abbie, 40). The women indicated there was an inequality associated with being a childless woman compared to those who were mothers. For example, "people who don't have kids tend to be considered more available for after-hours work and things like that" (Maree, 42) and "there are no benefits, there are no discounts on anything, no breaks...insurance and things like that...I kind of feel a bit ripped off as well financially" (Lara, 43).

\section{Reproductive history}

Most women (90\%) were not trying to get pregnant and the majority of women $(76 \%)$ had never tried to get pregnant. Fertility problems were reported by $12 \%$ of women, with $12 \%$ of women reporting seeking help or treatment for problems with fertility (including single women). During their lifetime, $6 \%$ of the women had experienced at least one miscarriage and $16 \%$ had undergone at least one termination of pregnancy. Table 3 shows the current reproductive health status for those women who intend to remain childless. 
Table 3

Women's Current Known Reproductive Health Status and Contraceptive Practices for Those Women who Intend to Remain Childless $(n=21)^{*}$

$\%(n)$

\section{Reproductive health status}

I have no male sexual partners now

My partner has had a vasectomy

I have found out that I or my partner cannot have children

\section{Contraceptive practices}

I do not need to or choose not to use contraception

I use the oral contraceptive pill for contraception

I use condoms for contraception

I use the oral contraceptive pill and condoms for contraception

* Only includes women who answered "yes" to the question "I do not wish to have children" or "I have never wanted to have children."

Less than half $(45.5 \%)$ of the women reported not needing to use any contraception (for example, they had undergone a hysterectomy, partner had had a vasectomy, or they were not engaged in heterosexual activity). A further $28 \%$ of women reported they chose not to use any contraception. Of the women who stated they did use contraception (54.5\%), 42\% used condoms and $36 \%$ used the oral contraceptive pill. Women were asked about a range of contraceptive practices including safe period / natural family planning (e.g. rhythm method, periodic abstinence etc.) and withdrawal methods. However none of the women reported using these methods. Table 3 shows for the women who did not want children, the oral contraceptive pill was used most frequently.

About two-thirds (65\%) of the women reported that if they were to become pregnant in the next 12 months they would have and keep the child. Only 6\% of the women indicated that they would terminate the pregnancy. The remaining women 
were unsure. Of the women who did not want to have children, $57.1 \%$ said they were unsure about what they would do if they became pregnant (Table 4).

Table 4

Future Actions on Unexpected Pregnancy by Childlessness Intentions

\begin{tabular}{|c|c|c|c|c|c|}
\hline & \multicolumn{3}{|c|}{$\begin{array}{l}\text { I do not wish to have children } \%(n) \\
\qquad n=45\end{array}$} & \multicolumn{2}{|c|}{$\begin{array}{l}\text { I have never wanted to have } \\
\text { children } \%(n) \\
n=44\end{array}$} \\
\hline & Yes & No & Not sure & Yes & No \\
\hline Have and keep the child & $28.6(6)$ & $100.0(10)$ & $84.6(11)$ & $38.1(8)$ & $82.6(19)$ \\
\hline Terminate the pregnancy & $14.3(3)$ & - & - & $14.3(1)$ & - \\
\hline Unsure & $57.1(12)$ & - & $15.4(2)$ & $47.6(10)$ & $17.4(4)$ \\
\hline
\end{tabular}

\section{Discussion}

Although this exploratory study provides valuable insight into women's reasons for childlessness, it is not without its limitations. The study was based on a small sample of childless women in Victoria, Australia, and the findings may not be generalised to other populations of childless women. Given the sample bias towards higher socioeconomic status (based on education and income) women's reasons for childlessness discussed here may not capture the full diversity of positions. Despite these limitations, the study has a number of strengths. The study has examined women's reasons for childlessness in the context of their reproductive lives and it has avoided the limitations of previous work by not categorising women with a type of childlessness during recruitment or the analysis of the data. This is important because women's reasons for childlessness are not straightforward, they are multifaceted and complex. While it may not possible to generalise the experiences of these women to the broader population of childless women, the congruence with other similar populations, discussed below, is a strength of this study.

This exploratory study found women's reasons for not having children are about choice and circumstance with only a small percentage of women reporting involuntary childlessness. A reason for childlessness reported by women in this study was not being in the 'right' relationship. Research by Cannold (2004, 2005) and Carmichael and Whittaker (2007a; 2007b) suggest some women attribute their 
childlessness to not finding 'Mr Right' and as a result are childless by circumstance. Similarly, Proudfoot and colleagues (2009) found women who were currently childless delayed childbearing due to relationship factors. However, findings from our study also suggest some women who are determined to become mothers will pursue this desire in the absence of a partner.

Being in a relationship where the partner did not wish to have children was also reported as a reason for childlessness in the present study. These findings are important as more than half of the women were either married or in a de facto relationship. Congruent with Veever's (1980) research, the present study suggests one of the reasons for women's childlessness is having a partner who does not wish to have children. However, Gillespie's (2003) qualitative research with voluntary childless women suggests it is women who make the decision to be childless, rather than their partners. It is possible the differences in the study findings may be a result of methodological approaches or the sample composition. For example, the present study did not label women with a type of childlessness and invited participation from women who did not have children regardless of their future pregnancy intentions. Gillespie's (2003) study consisted of women who had previously identified themselves as voluntarily childless.

Women's reasons for childlessness were also a result of a lack of desire to have children and wanting to be able to live their own lives. This is supported by Maher and Saugeres (2007) who suggest childless women are afraid motherhood will take over and disrupt their lives resulting in a loss of their identity. Similar to previous research (Campbell, 1985; Ireland, 1993; Maher \& Dever, 2004; McQuillan, Greil, Shreffler, \& Tichenor, 2008) these findings diverge from the stereotype of a childless woman where she is seen as career focused with a dislike of children and accordingly choosing to be childfree. Rather, women's reasons for childlessness are mainly about circumstance and life choice.

Interestingly, the findings indicate women's decisions about childbearing intentions are more stable than expected. Of the childless women in the study almost half did want to have children, with the majority of these women reporting consistency in their childlessness intentions. Further to this, women were either clear about their childlessness intentions and made a conscious decision or they described it as a result of 'fate'. This is consistent with other research which 
categorises childless women as 'early articulators' or 'postponers' (Maher \& Saugeres, 2007; Tietjens-Meyers, 2001). Arguably, women who are childless as a result of 'fate' are not 'postponers' per se but rather childless by life choice and circumstance as the term 'postponers' assumes women will inevitably become mothers. This is an important finding as it suggests women's decisions about being and remaining childless across the reproductive years are the result of women's desires about her life and that infertility, relationship status, partner's wishes or career aspirations play a smaller role in women's reproductive decision-making. Furthermore, it is possible that life circumstances are a justification for childlessness offered in response to the negative stereotyping and stigma associated with voluntary childlessness. However, this requires further investigation.

While women may experience choice in relation to their childbearing intentions, society portrays this decision as deviant if it diverges from motherhood. The women in this study expressed this as not knowing who they were or where they fitted if they were a woman without children, despite the societal perception that there is greater choice for women (Australian Bureau of Statistics, 2008; Gillespie, 2003; Gray, Qu, \& Weston, 2008; Hakim, 2003; Seccombe, 1991). The women in this study believed childlessness was considered a stigmatised position and as such, they felt a need to justify their position. This is consistent with previous research (Doyle, Pooley, \& Breen, 2012; Maher \& Saugeres, 2007; Rich, Taket, Graham, \& Shelley, 2011; Simpson, 2007; Tietjens-Meyers, 2001). Further, Morell (1994, p. 305) suggests women must 'constantly engage in acts of subversion if they pursue goals that are not stereotypically "feminine"'. Park (2005) equates this subversion with dominant pronatalist ideology: 'the context of continuing pronatalism... requires many childless individuals to engage in information control and stigma management techniques, tailored to particular audiences, to manage their deviant identities' ( $p$. 372).

A key mechanism by which social exclusion emerges is through stigma (Taket, et al., 2009). Stigma has been defined as a 'deeply discrediting attribute that globally devalues an individual' (Goffman, 1963, p.12). These attributes become associated with discrediting dispositions (negative evaluations and stereotypes) and then become the basis for social exclusion and / or avoidance of the group members "marked" with the discrediting disposition (Major \& O'Brien, 2005). Given this, it is not 
surprising women questioned their identity as a woman without children and where they 'fitted' in a pronatalist society. Stigma surrounding childlessness has been found to lead to feelings of incompleteness and that others perceived them as desperate, pitiful and selfish (Letherby, 1999).

Interestingly, of those women who did not want to have children, almost half chose not to use or felt they did not need to use contraception. There are many possible explanations for this finding including not being in a heterosexual relationship at the time of the study, having undergone a hysterectomy or tubal ligation, infertility or having a partner who has had a vasectomy. However, this accounts for only about half of the women. Therefore, it is unclear how women who do not want children will remain childless if they are not using contraception. Data from the Australian Longitudinal Study on Women's Health found that young women (aged 22-27 years) who wanted to remain childless were less likely to use contraception compared to those who intended to become mothers (Lee \& Gramotnev, 2006). In the current study most women who did not want children were unsure what they would do if they were to become pregnant. This data suggests that the contraceptive practices of women during their reproductive years who are childless voluntarily and by circumstance warrant further investigation.

\section{Conclusion}

This study suggests while for many women childlessness is about choice and circumstance, women also feel the need to explain and justify their childless status. Furthermore, these findings indicate childless women are stigmatised and socially excluded. This is an important finding and highlights the need to further investigate what the implications, stigma and social exclusion has on childless women's health and wellbeing. Finally, the findings provide insight into women's reasons for childlessness and challenge some of the stereotypical views held about women's reasons for childlessness, particularly in relation to the view childless women are career-focused and childless women chose a career over childbearing. 


\section{References}

Anderson, M., J. (2007). Fertility futures: Implications of national, pronatalist policies for adolescent women in Australia. Paper presented at the International Women's Conference: Education, employment, and everything - the triple layers of a woman's life, Toowoomba, QLD, Australia.

Australian Bureau of Statistics. (2002). Australian social trends 2002. Canberra: Australian Bureau of Statistics.

Australian Bureau of Statistics. (2007). Births 2006. Canberra: Australian Bureau of Statistics.

Australian Bureau of Statistics. (2008). Australian social trends 2008: How many children have women in Australia had? (Cat. No. 4102.0). Canberra: Australian Bureau of Statistics.

Becker, G., \& Nachtigall, R. (1992). Eager for medicalisation: The social production of infertility as a disease. Sociology of Health \& IIIness, 14(4), 456-471.

Berrington, A. (2004). Perpetual postponers? Women's, men's and couple's fertility intentions and subsequent fertility behaviour. Population Trends, Autumn 2004, (117), 9-19.

Biddlecom, A., \& Martin, S. (2006). Childless in America. American Sociological Association, 5(4), 54.

Boddingtom, B., \& Didham, R. (2007). Busy making other plans: Increases in childlessness in New Zealand. Demographic Trends.

Boddingtom, B., \& Didham, R. (2009). Increases in childlessness in New Zealand. Journal of Population Research, 26, 131-151.

Braun, V., \& Clarke, V. (2006). Using thematic analysis in psychology. Qualitative Research in Psychology, 3, 77-101.

Campbell, E. (1985). The Childless marriage: An exploratory study of couples who do not want children. London: Tavistock.

Cannold, L. (2004). Declining marriage rates and gender inequity in social institutions: towards an adequately complex explanation for childlessness. People and Place, 12(4), 1-11.

Cannold, L. (2005). What, no baby? Why women are losing the freedom to mother, and how they can get it back. Freemantle: Curtin University Books.

Carey, G., Graham, M., \& Shelley, J. (2009). Discourse, power and exclusion: the experiences of childless women. In A. Taket, B. Crisp, A. Nevill, G. Lamaro, M. Graham \& S. Barter-Godfrey (Eds.), Theorising social exclusion. London: Routledge.

Carmichael, G., A, \& Whittaker, A. (2007a). Forming relationships in Australia: Qualitative insights into a process important to human wellbeing. Journal of Population Research, 24(1), 23-49.

Carmichael, G. A., \& Whittaker, A. (2007b). Choice and circumstance: Qualitative insights into contemporary childlessness in Australia. European Journal of Population, 23, 111-143.

Daniluk, J. (2001). Reconstructing their lives: A longitudinal, qualitative analysis of the transition to biological childlessness for infertile couples. Journal of Counseling \& Development, 79(4), 439-449.

Dever, M. (2005). Baby talk: The Howard government, families, and the politics of difference. Hecate, 31(2), 45-61. 
Doyle, J., Pooley, J. A., \& Breen, L. (2012). A phenomenological exploration of the childfree choice in a sample of Australian women. Journal of Health Psychology, 18(3), 397-407.

Dye, J. (2008). Fertility of American women: 2006 Population Reports (Vol. August 2008, pp. 1-23). Washington, DC, USA: US Census Bureau, Department of Commerce.

Earle, S., \& Letherby, G. (2007). Conceiving Time? Women who do or do not concieve. Sociology of Health \& Illness, 29(2), 233-250.

Gillespie, R. (2000). When no means no: Disbelief, disregard and deviance as discourses of voluntary childlessness. Women's Studies International Forum, 23(2), 223-234.

Gillespie, R. (2003). Childfree and feminine: Understanding the gender identity of childless women. Gender and Society, 17(1), 122-136.

Goffman, E. (1963). Stigma notes on management of a spoiled identity. Middlesex: Penguin Books.

Gray, M., Qu, L., \& Weston, R. (2008). Fertility and family policy in Australia. Melbourne: Australian Institute of Family Studies.

Hakim, C. (2003). A new appropach to explaining fertility patterns: Preference theory. Population and Development Review, 29(3), 349-374.

Heard, G. (2006). Pronatalism under Howard. People and Place, 14(3), 12-25.

Houseknecht, S. K. (1979). Childlessness and marital adjustment. Journal of Marriage and the Family, 41(2), 259-265.

Ireland, M. (1993). Reconceiving women: Separating motherhood from female identity. New York: Guilford.

Jackson, N., \& Casey, A. (2009). Procreate and cherish: A note on Australia's abrupt shift to pro-natalism. New Zealand Population Review, 35, 129-148.

Laws, P. J., Liz, Z., \& Sullivan, E. A. (2010). Australia's mothers and babies 2008. Perinatal statistics series no. 24. (Cat. no. PER 50). Canberra: Australian Insitute of Health and Wellbeing.

Lee, C., \& Gramotnev, H. (2006). Motherhood plans among young Australian women: Who wants children these days? Journal of Health Psychology, 11(1), 5-20.

Letherby, G. (1999). Other than mother and mothers as others: The experience of motherhood and non-motherhood in relation to 'infertility' and 'involuntary childlessness'. Women's Studies International Forum, 22(3), 359-372.

Letherby, G. (2002). Challenging dominant discourses: Identity and change and the experience of 'infertility' and 'involuntary childlessness'. Journal of Gender Studies, 11(3), 277-288.

Liamputtong, P., \& Ezzy, D. (2005). Qualitiative research methods (2 ${ }^{\text {nd }}$ ed.). Melbourne: Oxford University Press.

Maher, J. M., \& Dever, M. (2004). What matters to women: Beyond reproductive stereotypes. People and Place, 12(3), 10-17.

Maher, J. M., \& Saugeres, L. (2007). To be or not to be a mother?: Women negotiating culutral representations of mothering. Journal of Sociology, 43(1), 5-20.

Major, B., \& O'Brien, L. T. (2005). The social psychology of stigma. Annual Review of Psychology, 56, 393-421.

Marshall, H. (1993). Not Having Children. Melbourne: Oxford University Press. 
McDonald, P. (1998). Contemporary fertility patterns in Australia: First data from the 1996 Census. People and Place, 6(1), 1-13.

McQuillan, J., Greil, A. L., Shreffler, K. M., \& Tichenor, V. (2008). The importance of motherhood among women in the contemporary United States. Gender \& Society, 22(4), 477-496.

Morell, C. (1994). Unwomanly conduct: The challenges of intentional childlessness. . Great Britain: Routledge.

Mosher, W., D., \& Bachrach, C., A. (1982). Childlessness in the United States. Journal of Family Issues, 3(4), 517-543.

Mueller, K., \& Yoder, J. (1997). Gendered norms for family size, employment, and occupation: Are there personal costs for violating them? Sex Roles, 36(3/4), 207-220.

Mueller, K., \& Yoder, J. (1999). Stigmatization of non-normative family size status. Sex Roles, 41(11/12), 901-919.

Park, K. (2002). Stigma management among the voluntary childless. Sociological Perspectives, 45(1), 21-45.

Park, K. (2005). Choosing childlessness: Weber's typology of action and motives of the voluntary childless. Sociological Inquiry, 75(3), 372-402.

Popay, J., Escorel, S., Hernández, M., Johnston, H., Mathieson, J., \& Rispel, L. (2008). Understanding and Tackling Social Exclusion. Final Report to the WHO Commission on Social Determinants of Health From the Social Exclusion Knowledge Network Retrieved from http://www.who.int/social determinants/knowledge networks/final reports/sek n final\%20report 042008.pdf

Proudfoot, S., Wellings, K., \& Glaiser, A. (2009). Analysis why nulliparous women over age 33 wish to use contraception. Contraception, 79, 98-104.

Rich, S., Taket, A., Graham, M., \& Shelley, J. (2011). 'Unnatural', 'unwomanly', 'uncreditable' and 'undervalued': The significance of being a childless woman in Australian society. Gender Issues, 28, 226-247. doi: DOI 10.1007/s12147011-9108-1

Rowland, R. (1982). An exploratoy study of the childfree lifestyle. Australian \& New Zealand Journal of Sociology, 18(1), 17-30.

Rowlands, I., \& Lee, C. (2006). Choosing to have children or choosing to be childfree: Australian students' attitudes towards the decisions of heterosexual and lesbian women. Australian Psychologist, 41(1), 55-59.

Sabatelli, R., Meth, R., \& Gavazzi, S. (1988). Factors mediating the adjustment to involuntary childlessness. Family Relations, 37(3), 338-343.

Seccombe, K. (1991). Assessing the costs and benefits of children: Gender comparisons among childfree husbands and wives. Journal of Marriage and the Family, 53(1), 191-202.

Simpson, R. (2007). 'Defying nature'?: Contemporary discourse around delayed childbearing and childlessness in Britain. GeNet Seminar: Low Fertility in Industrialised Countries: London School of Economics. Centre for Research on Families and Relationships, Edinburgh.

Smith, A. M. A., Pitts, M. K., Shelley, J. M., Richters, J., \& Ferris, J. (2007). The Australian longitudinal study of health and relationships. BMC Public Health, 7, 139-142.

Somers, M., D. (1993). A comparison of voluntary childfree adults and parents. Journal of Marriage and the Family, 55(3), 634-650. 
Taket, A., Crisp, B., Nevill, A., Lamaro, G., Graham, M., \& Barter-Godfrey, S. (2009). Theorising social exclusion. London: Routledge.

Tietjens-Meyers, D. (2001). The rush to motherhood - pronatalist discourse and women's autonomy. Signs: Journal of Women in Culture \& Society, 26(3), 735-773.

Ulrich, M., \& Weatherall, A. (2000). Motherhood and infertility: Viewing motherhood through the lens of infertility. Feminism \& Psychology, 10(3), 323-336.

Veevers, J. (1980). Childless by choice. Canada: Butterworth \& Co. Ltd.

Women's Health Australia. (2000). Second survey for women in their 20's. University of Newcastle, New South Wales, Australia: Australian Longitudinal Study on Women's Health.

Women's Health Australia. (2006). Fourth survey for young women University of Newcastle, New South Wales, Australia: Australian Longitudinal Study on Women's Health.

\section{Biographical Notes}

Dr Melissa Graham is a Senior Lecturer and member of the Centre for Health through Action on Social Exclusion (CHASE) in the School of Health and Social Development, Deakin University. Dr Graham has a particular interest in women's reproductive health including childlessness and social exclusion.

Ms Erin Hill is a Research Assistant in the Centre for Health through Action on Social Exclusion (CHASE) in the School of Health and Social Development, Deakin University.

Associate Professor Julia Shelley holds the position of Deputy Director, Centre for Health through Action on Social Exclusion (CHASE) in the School of Health and Social Development, Deakin University. Associate Professor Shelley is a social epidemiologist who has worked in the areas of reproductive health, women's health and health services research for more than 20 years.

Professor Ann Taket holds a chair in Health and Social Exclusion within the School of Health and Social Development, and is Director of the Centre for Health through Action on Social Exclusion (CHASE). Professor Taket has over thirty years' experience in public health related research, with particular interests in research directed at understanding the complex interactions between social exclusion and health, in the design and evaluation of interventions to reduce health inequalities, the 
use of action research, participatory methods, and experiential learning, and prevention and intervention in violence and abuse. 